\title{
Cold accumulators in air conditioning systems
}

\author{
Dmitriy Shlychkov* \\ Moscow State University of Civil Engineering, Yaroslavskoe sh., 26, Moscow, 129337, Russia
}

\begin{abstract}
The appropriateness of using cold accumulators in air conditioning systems has been assessed. A cooling system with a storage tank is considered, in which ice is frozen on the outer surface of the evaporator heat exchange tubes. It is established that the accumulation of cold can lead to a significant reduction in cash costs. The analysis of the experience of using cold accumulators in air conditioning systems allows drawing the following conclusions: the most common solution for accumulating cold is the use of ice accumulators with ice freezing on the heat exchange surface of evaporators located in the storage tank; the melting mode of ice in ice accumulators with the chiller turned off is adopted in designing. The area of the heat exchange surface of the ice accumulator apparatus during cooling of ice water should be determined mainly depending on the conditions of ice melting; to freeze ice, it is necessary to increase the heat exchange surface area of the evaporator and lower the boiling point to minus $10 \ldots 15{ }^{\circ} \mathrm{C}$. Specific energy costs $(\mathrm{kW}$ of electricity per $\mathrm{kW}$ of cold) increase by 2 or more times, which reduces profit.
\end{abstract}

\section{Introduction}

Cold supply systems, including air conditioning of buildings, operate in a sharply variable schedule of cold consumption, i.e. with peak heat load on the refrigeration unit (Fig. 1 [1]). The use of cold accumulators (CA) as part of a refrigeration unit is one of the modern effective ways to reduce the cost of a cold supply system. The use of CA allows smoothing out the unevenness of the thermal load on the refrigeration equipment and reducing the refrigeration capacity of the installed equipment. At the same time, during the nighttime minimum of external heat inflows and energy consumption, water ice freezes (or the coolant is cooled), the refrigeration potential of which is used during the daytime peak of thermal loads of the consumer of cold and peak of electricity consumption.

\section{Methods}

Nowadays, the use of cold accumulators is not widely used in construction, despite the obvious advantages of such a system.

* Corresponding author: stok-n@mail.ru 
In [2-7], the appropriateness of the use of cold accumulators in HVAC systems was assessed. With a share of cold accumulation of $\sim 0.4$, a decrease in initial investment and annual operating costs can reach $40 \div 45 \%$.

Increasing energy tariffs, introducing reduced night tariffs, etc. contribute to the expansion of using refrigeration circuits with cold accumulators.

Mostly the use of cold accumulators is constrained by the lack of widespread practice in designing such systems. These systems require a more thorough approach to the design of automatic control systems.

\section{Results and Discussion}

Refrigeration unit with cold accumulators consists of a compressor, condenser, evaporator and storage tank. An analysis of the design and operational features of the cold accumulators of various designs made it possible to single out a group of effective batch cold accumulators with ice freezing on the outer surface of the evaporator heat transfer tubes (Fig. 2)

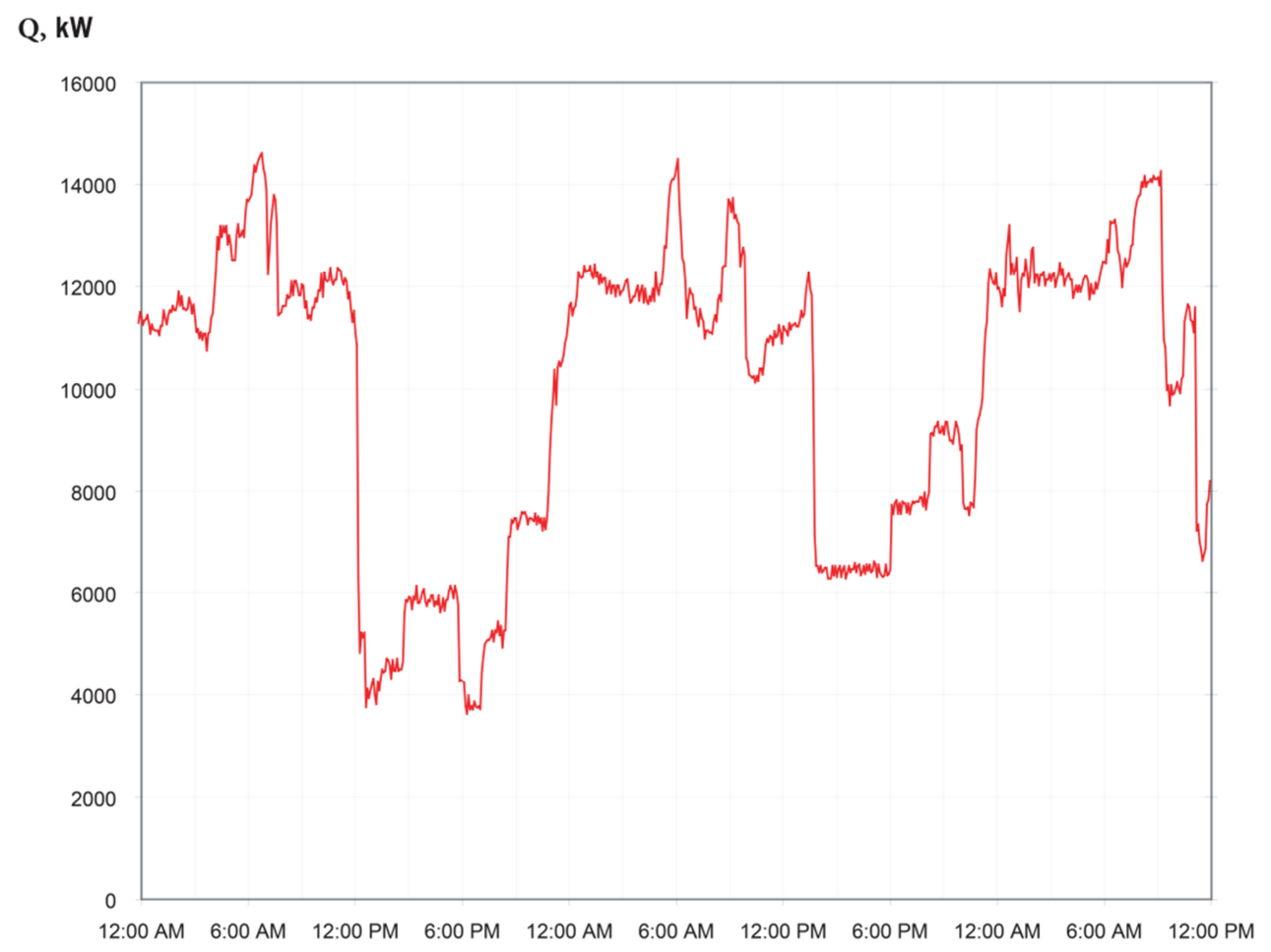

Fig. 1. Thermal load on the cold supply system

The coolant of the air conditioning system circulates through the coils immersed in the tank with water (storage tank, ice plant). During the charging cycle, ice forms on the outer surface of the evaporator heat transfer tubes until a satisfactory thickness is reached (usually 50 to $70 \mathrm{~mm}$ ). During normal operation, cooled water circulates in the air cooler of the central air conditioner (load), and ice remains in the cold accumulator. During the discharge cycle, water flows through the storage tank and is cooled by melting ice. Cold accumulators are simple in design, reliable and easy to use. 
Compared to water storage tanks, ice storage tanks can accumulate more cold. Thus, it is possible to reduce the area and volume of rooms.

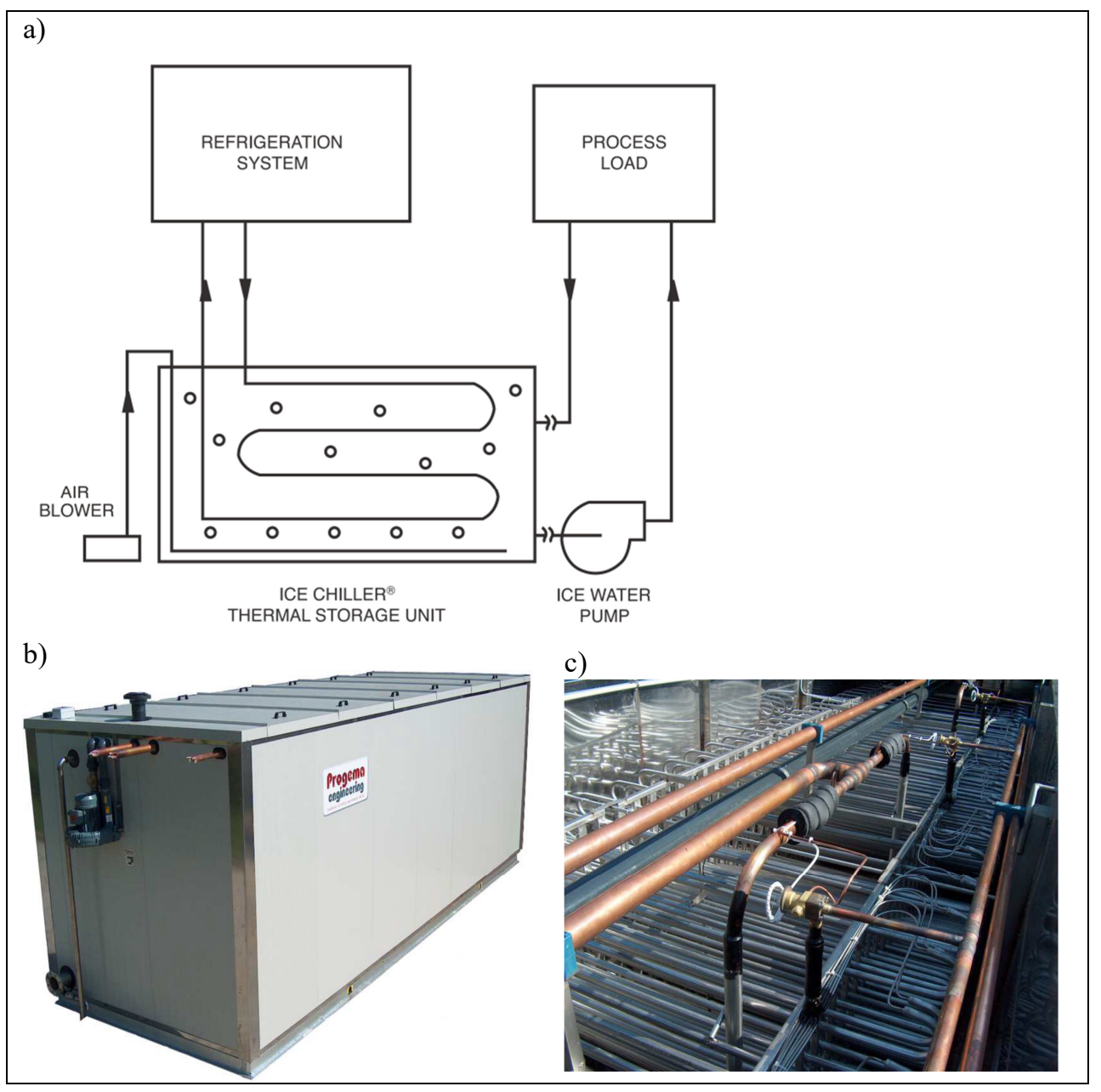

Fig. 2. Ice making plant of the cold supply system

a - schematic diagram of a cold supply system [8]; b, c - storage tank [9] plant.

The specific energy consumption is taken as the main energy indicator of the ice making

$$
N=\frac{N_{c}+N_{i}}{i_{i} \cdot G_{i}}, \mathrm{~kW} / \mathrm{kW},
$$

where $N_{c}$ - energy consumption for a compressor-condenser unit, $\mathrm{kW} ; N_{i}$ - energy consumption for additional equipment, $\mathrm{kW} ; i_{i}$ - enthalpy of ice (relative to water entering the storage tank), kJ/kg; $G_{i}$ - ice plant productivity, $\mathrm{kg} / \mathrm{s}$.

The specific energy consumption for producing $1 \mathrm{~kg}$ of ice 


$$
n=\frac{N_{c}+N_{i}}{G_{i}}, \mathrm{~kJ} / \mathrm{kg}
$$

For industrial ice making plants $n=145 \ldots .290 \mathrm{~kJ} / \mathrm{kg}$.

The specific cold consumption for producing $1 \mathrm{~kg}$ of ice

$$
q_{i}=i_{i}+\sum q_{l o s}, \mathrm{~kJ} / \mathrm{kg} .
$$

where $\sum q_{\text {los }}$ - specific losses of cold during separation of ice into the external environment to compensate for heat, for example, from a water circulation pump.

For industrial ice making plants $q_{i}=460 \ldots 840 \mathrm{~kJ} / \mathrm{kg}$.

The specific energy consumption for ice making depends on the temperature. At a high water temperature, it is preferable to pre-cool it in water-cooling devices at an increased (in comparison with an icemaker) boiling point of the coolant and in the absence of thermal resistance of the frozen ice layer.

The limit of a reasonable increase in the boiling temperature directly in the icemakers is determined mainly by the ratio of the costs of the icemaker, compressor-condenser unit with drive, industrial premises and energy consumption.

The limit of permissible freezing temperature decrease is determined by technological requirements. It should be borne in mind that a change in the boiling point has the greatest effect on the intensity of ice freezing.

\section{Conclusions}

The analysis of the experience of using cold accumulators in air conditioning systems allows drawing the following conclusions:

- the most common solution for accumulating cold is the use of ice accumulators with ice freezing on the heat exchange surface of evaporators located in the storage tank;

- the melting mode of ice in ice accumulators with the chiller turned off is adopted in designing. The area of the heat exchange surface of the ice accumulator apparatus during cooling of ice water should be determined mainly depending on the conditions of ice melting;

- to freeze ice, it is necessary to increase the heat exchange surface area of the evaporator and lower the boiling point to minus $10 \ldots 15^{\circ} \mathrm{C}$. Specific energy costs $(\mathrm{kW}$ of electricity per $\mathrm{kW}$ of cold) increase by 2 or more times, which reduces profit.

\section{References}

1. Wang S., Gu, J., Dickson T. Model to Simulate the Behavior of Accumulators in Automotive Air Conditioning Systems. SAE Technical Papers. (2005) DOI 10.4271/2005-01-2047

2. Karpis E.E. Energy saving in air conditioning systems. (Stroyizdat, Moscow, 1986)

3. Broyda V.A. The expediency of the air conditioning system with cold accumulation. Izvestiya KGASU. 2(36) , 127-132 (2016).

4. Naumov A.L., Seliverstov Y.M., Efremov V.V., Protasov G.V. Air conditioning systems with cold accumulators, AVOK, 2012, 3, 52-56.

5. Seliverstov Y.M., Efremov V.V. Economics of air conditioning systems with cold accumulators. AVOK, 1, 30-33 (2013).

6. Bondar E.S., Kalugin P.V. Energy-saving air-conditioning system with cold accumulation. SOK, 3, 44-48 (2006) 
7. Mehling H., Cabeza L.F.: Heat and cold storage with PCM. Springer 2008.

8. Ikem, I.A. Optimization of the energy characteristics of a chiller with cold accumulator in tropical climate. Polythematic Online Scientific Journal of Kuban State Agrarian University. (2016) DOI: 10.21515/1990-4665-123-084

9. V.F. Ochkov, T.A. Stepanova, G.M. Katenev, V.A. Tumanovskii, P.N. Borisova. Study of Cycling Air-Cooling System with a Cold Accumulator for Micro GasTurbine Installations. Thermal engineering Vol. 65 No. 52018

10. Alpatov, V., Lukin, A., Chernyshev, D., Shirokov, V.: Analysis of the hardness of node connections of metal constructions using modern CAE-systems. In: IOP Conference Series: Materials Science and Engineering 456(1), p. 012010 (2018). DOI: $10.1088 / 1757-899 \mathrm{X} / 456 / 1 / 012010$

11. Alpatov, V., Balzannikov, M., IOP Conference Series: Materials Science and Engineering 456(1), p. 012011 (2018). DOI: 10.1088/1757-899X/456/1/012011

12. Alpatov, V. Y., Veremeenko, O. Y., Sakharov, A. A., Shirokov, V. S, MATEC Web of Conferences. 86, 02015 (2016). DOI: 10.1051/matecconf/20168602015 